\title{
A Marujada de São Benedito de Bragança-PA: cores e sonoridades de uma tradição ancestral
}

\author{
The Marujada of São Benedito in \\ Bragança-PA: colors and sonorities \\ of an ancestral tradition
}

Ronney Alano Pinto dos Reis Mestrando em Filosofia - PPGFIL/UFPA ronneyalano@hotmail.com 
Desde a primeira vez que visitei Bragança-PA, a pérola do Caeté ${ }^{1}$ no início de 2014, me parecera claro, como em qualquer outra época, que a atmosfera local girava em torno de uma antiga tradição ${ }^{2}$, cujo ponto alto ocorre nos dias 25 e 26 de dezembro ${ }^{3}$ de cada ano. É a Marujada de São Benedito - "o santo preto"! Pelas ruas, casas, janelas e também envoltos nos corpos dos convivas dessa grande celebração, que tem suas raízes na religiosidade ancestral do povo negro bragantino, os traços de um tempo festivo e vibrante de cores e sonoridades modificam a paisagem cotidiana por meio de práticas sociais e culturais de homens, mulheres e crianças, que, com suas vestes marujas, dão continuidade ao legado da Irmandade de São Benedito de Bragança ${ }^{5}$, seguindo a imagem do santo em procissão pelas ruas da cidade.

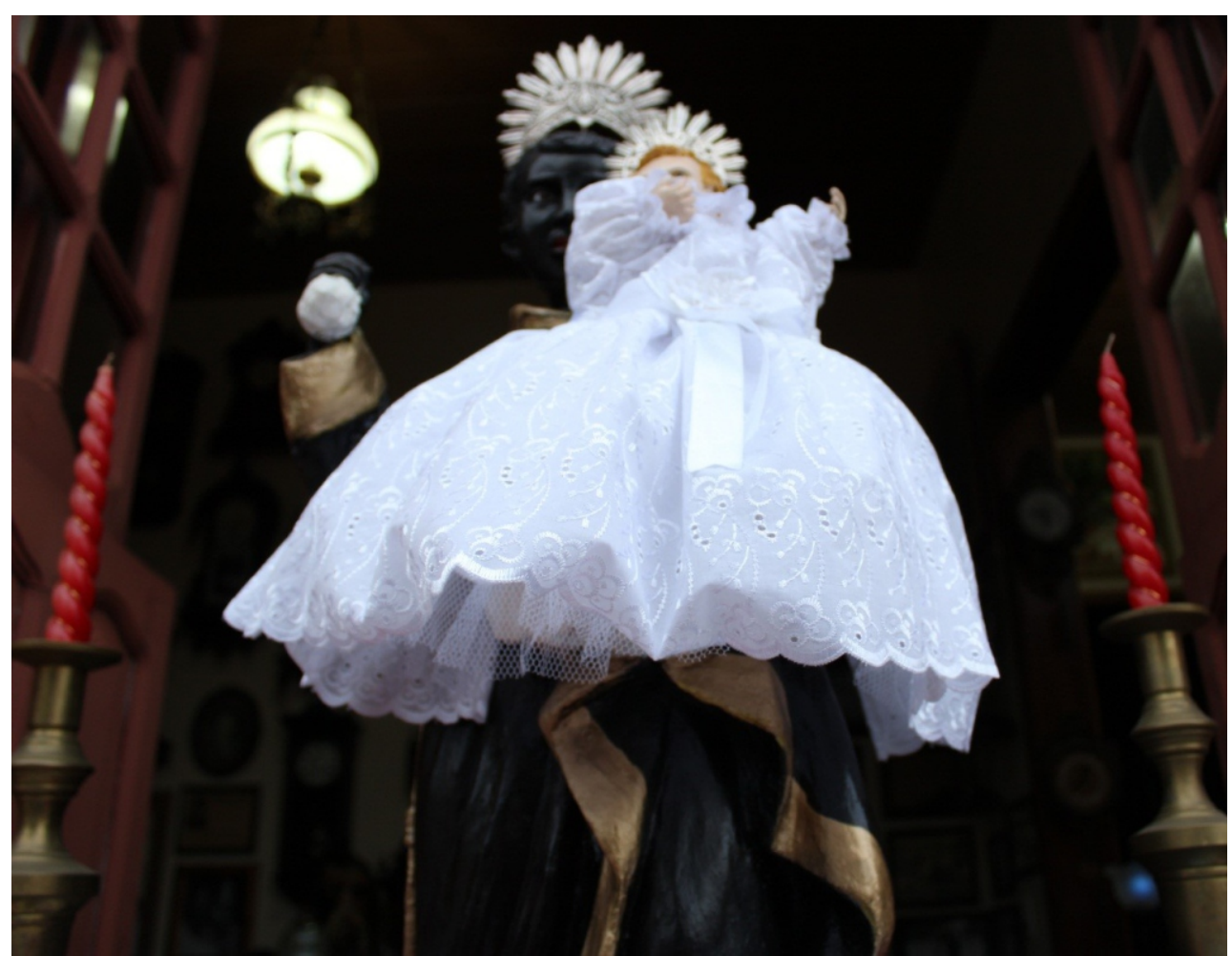

Efígie de São Benedito na janela: signo de devoção e de antigas marcas de distinção social ${ }^{6}$. Foto: Ronney Alano. 
A Marujada de São Benedito de Bragança-PA: cores e sonoridades de uma tradição ancestral

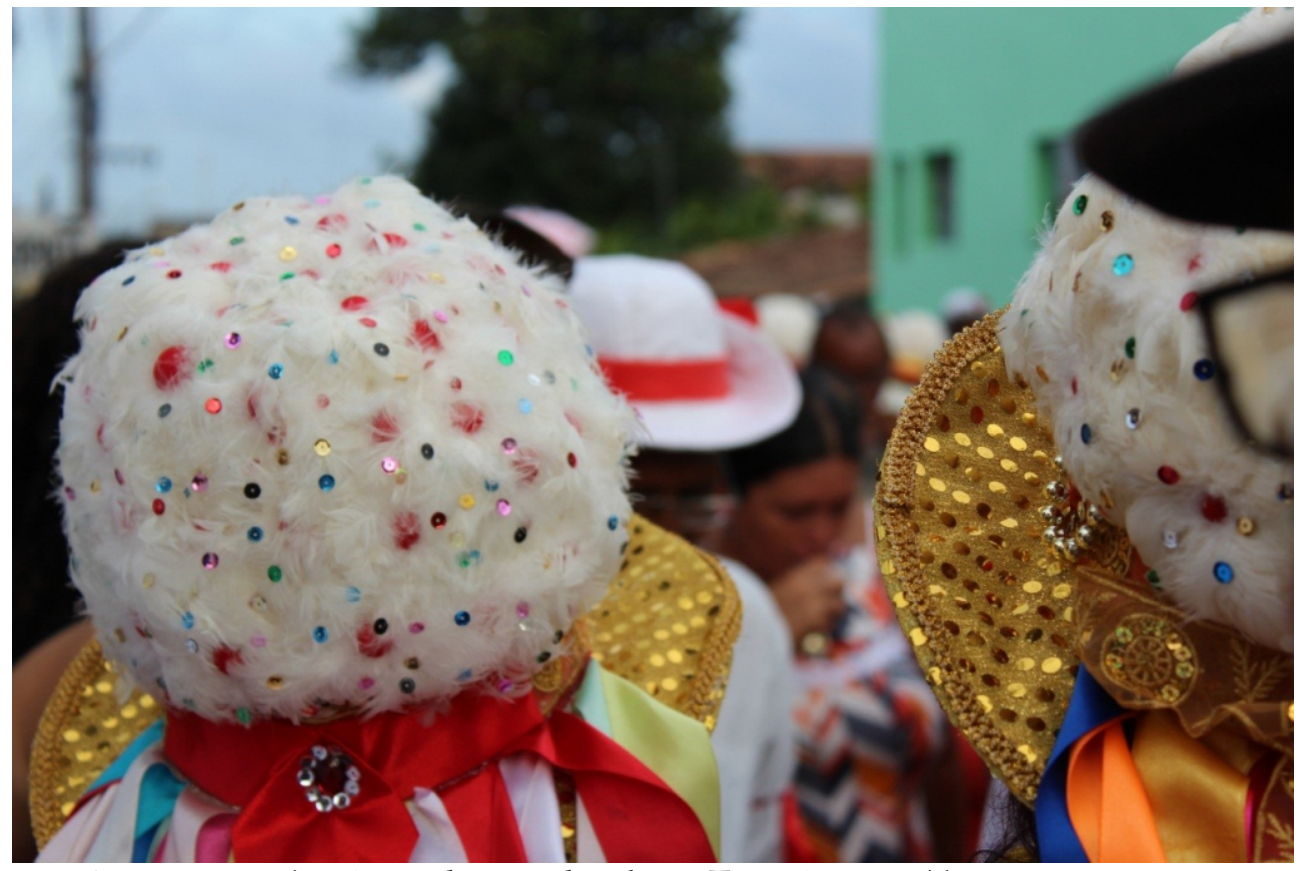

Marujas com seus chapéus e adereços de cabeça. Foto: Ronney Alano.

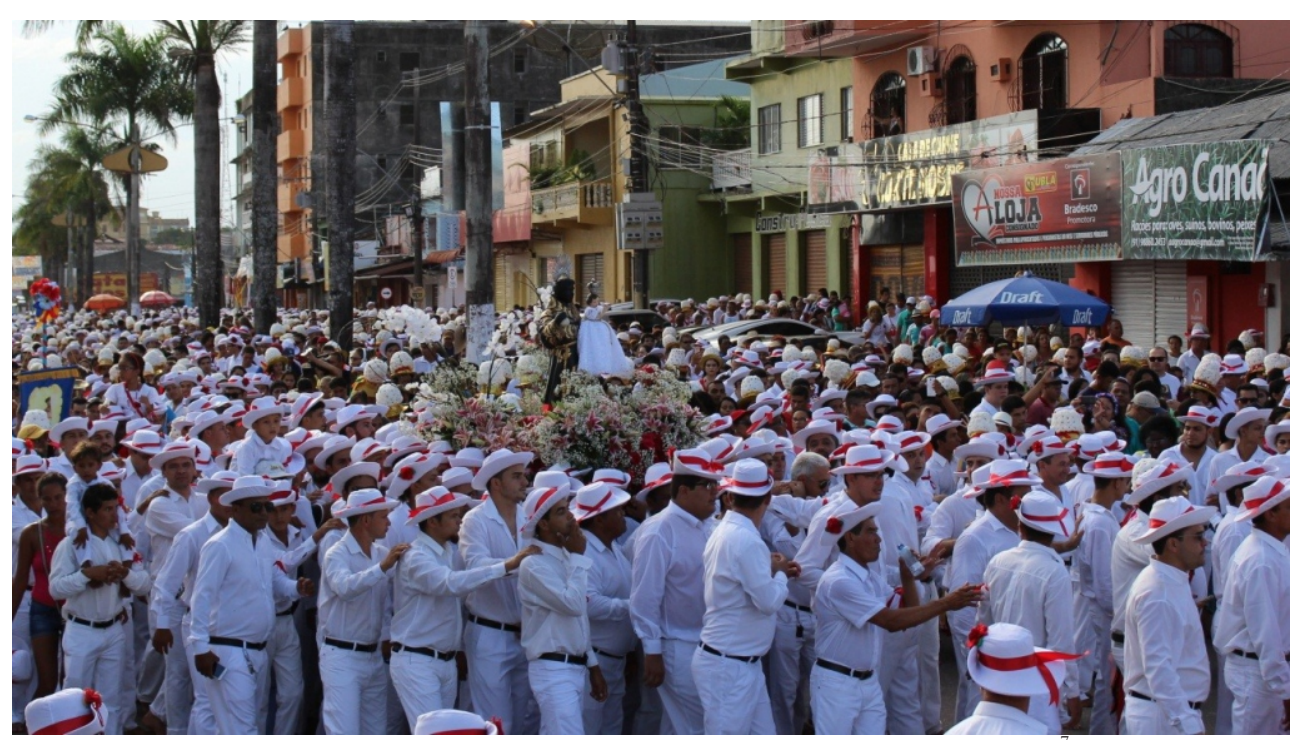

Marujos são o mar de São Benedito em procissão pelas ruas de Bragança . Foto: Ronney Alano. 


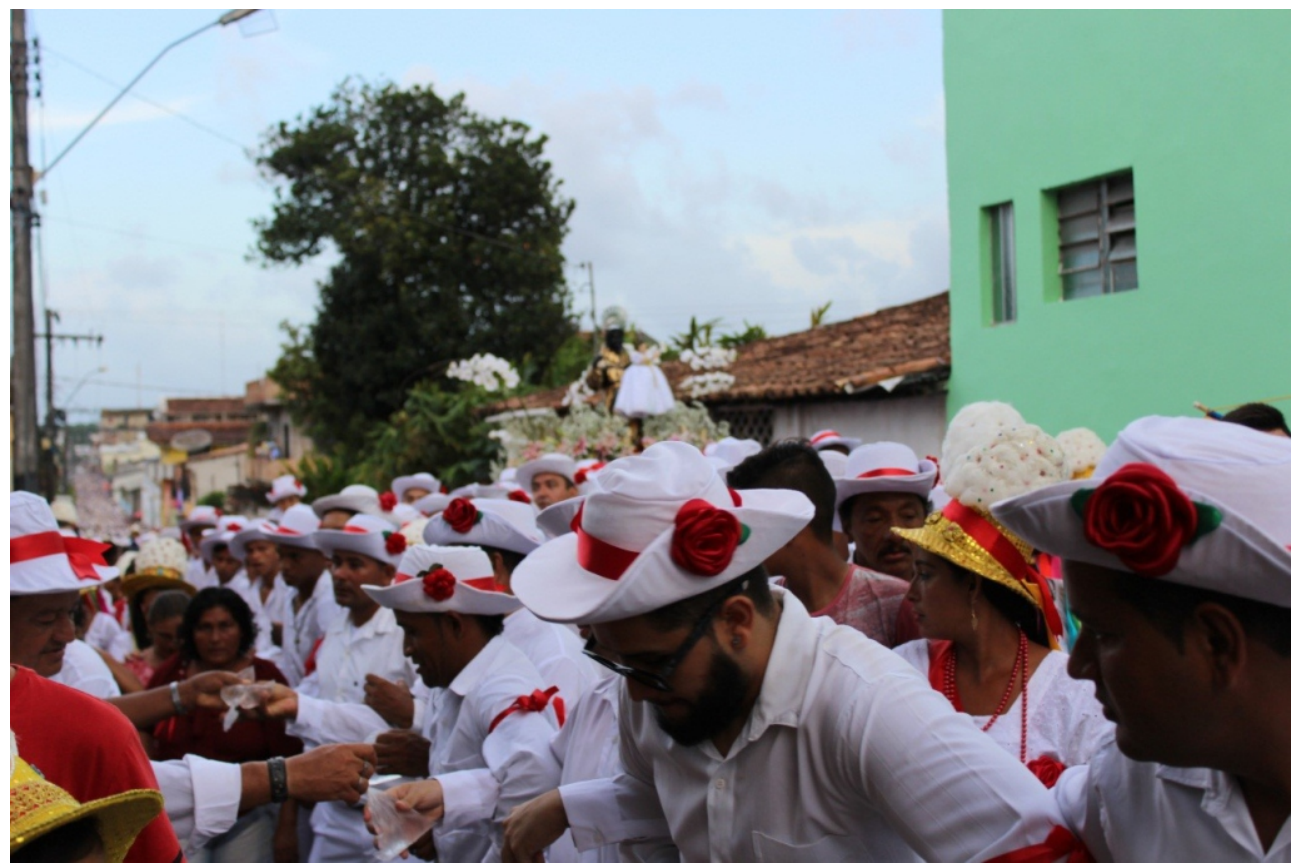

São Benedito e sua escolta. Foto: Ronney Alano.

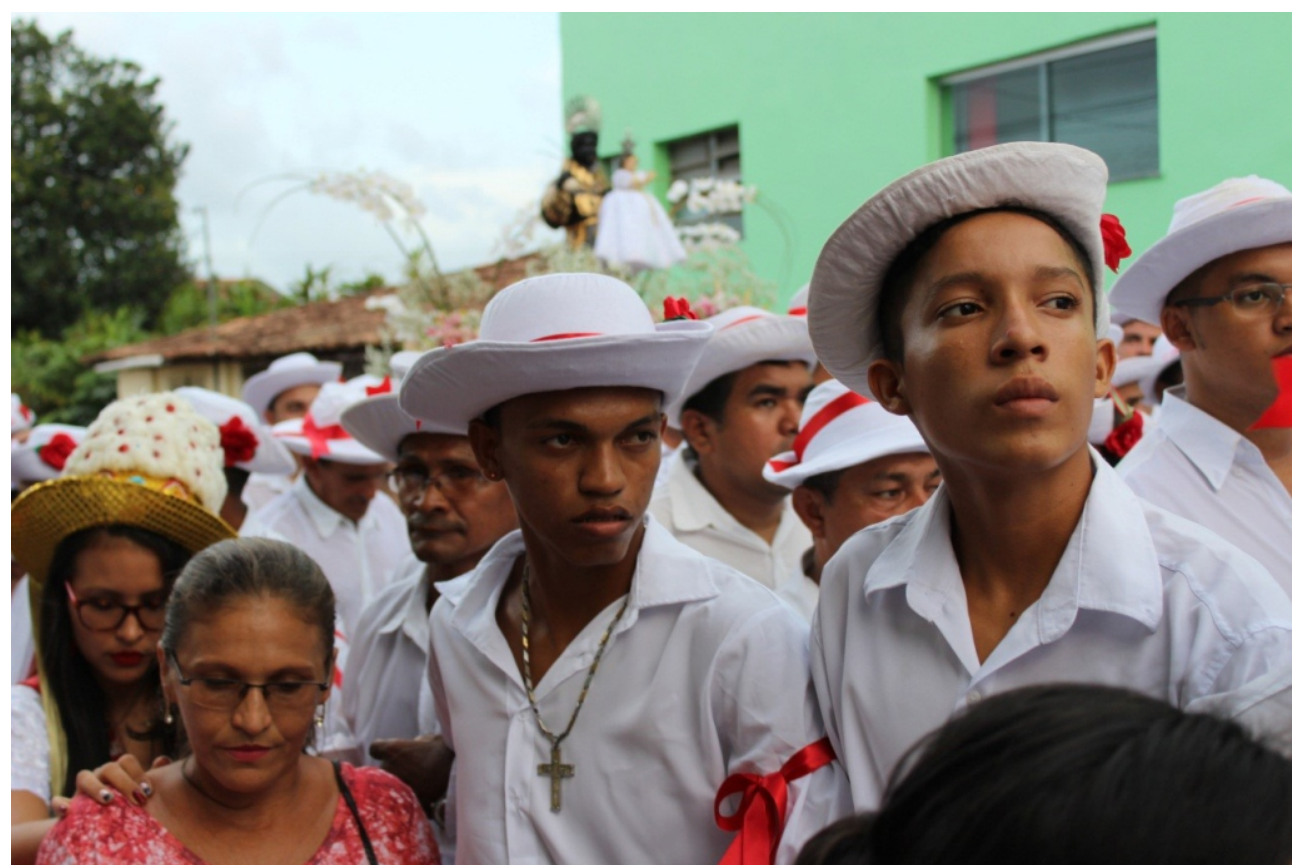

Nos rostos, uma tradição atravessa gerações. Foto: Ronney Alano. 
A Marujada de São Benedito de Bragança-PA: cores e sonoridades de uma tradição ancestral

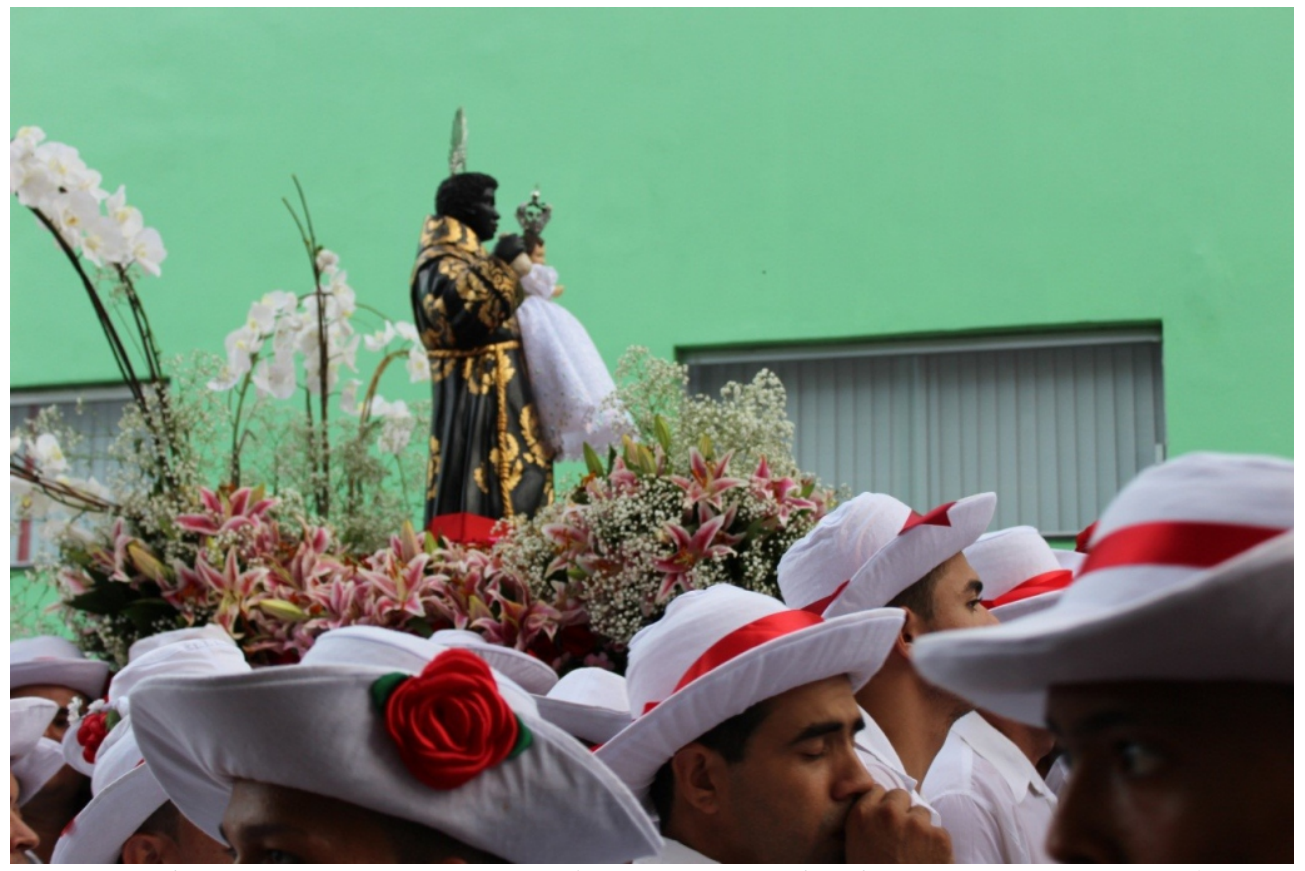

Em seu andor, o santo parece flutuar sobre os chapéus dos devotos. Foto: Ronney Alano.

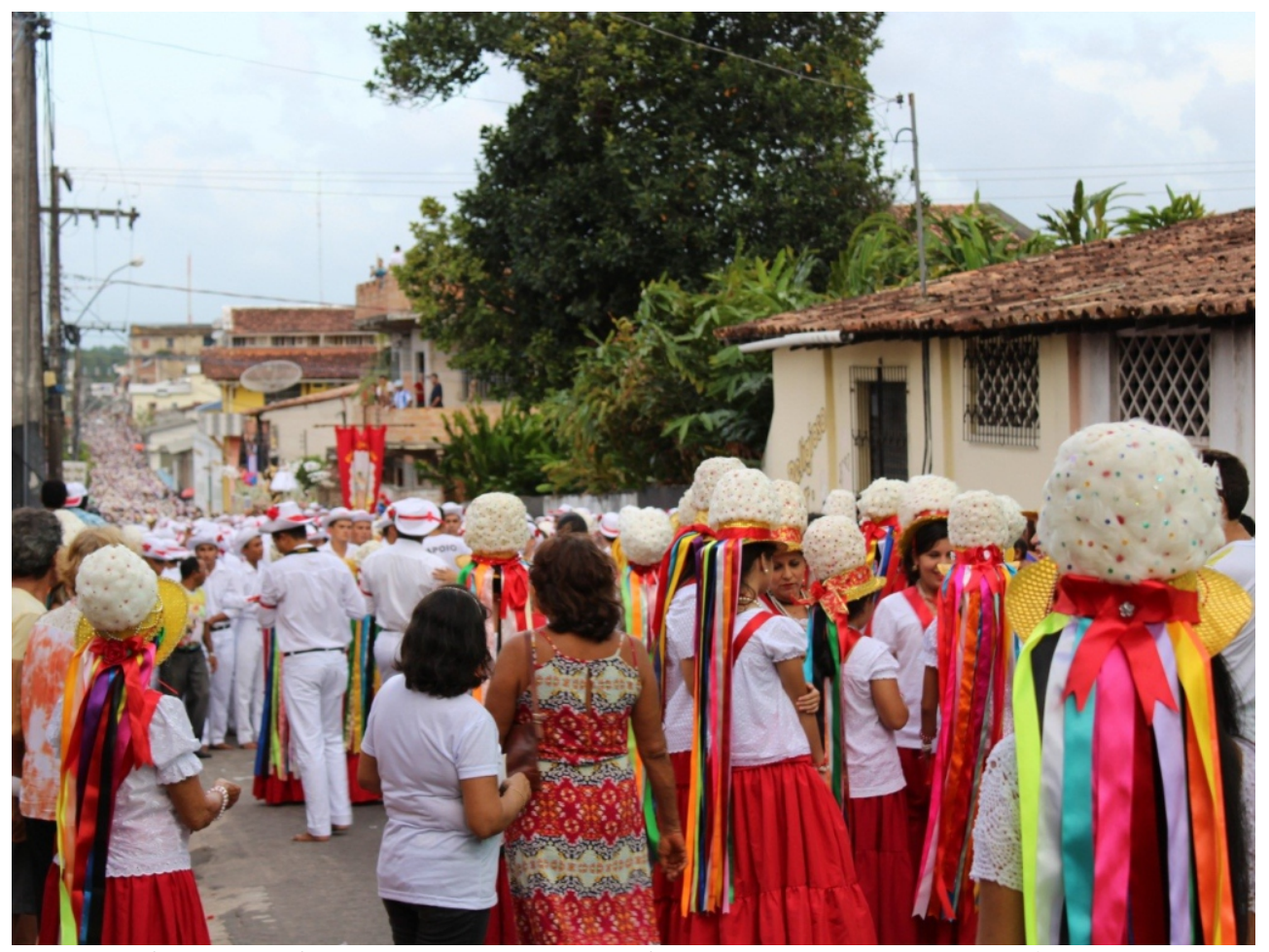

Marujas, descontraídas, esperam a passagem da procissão. Foto: Ronney Alano. 


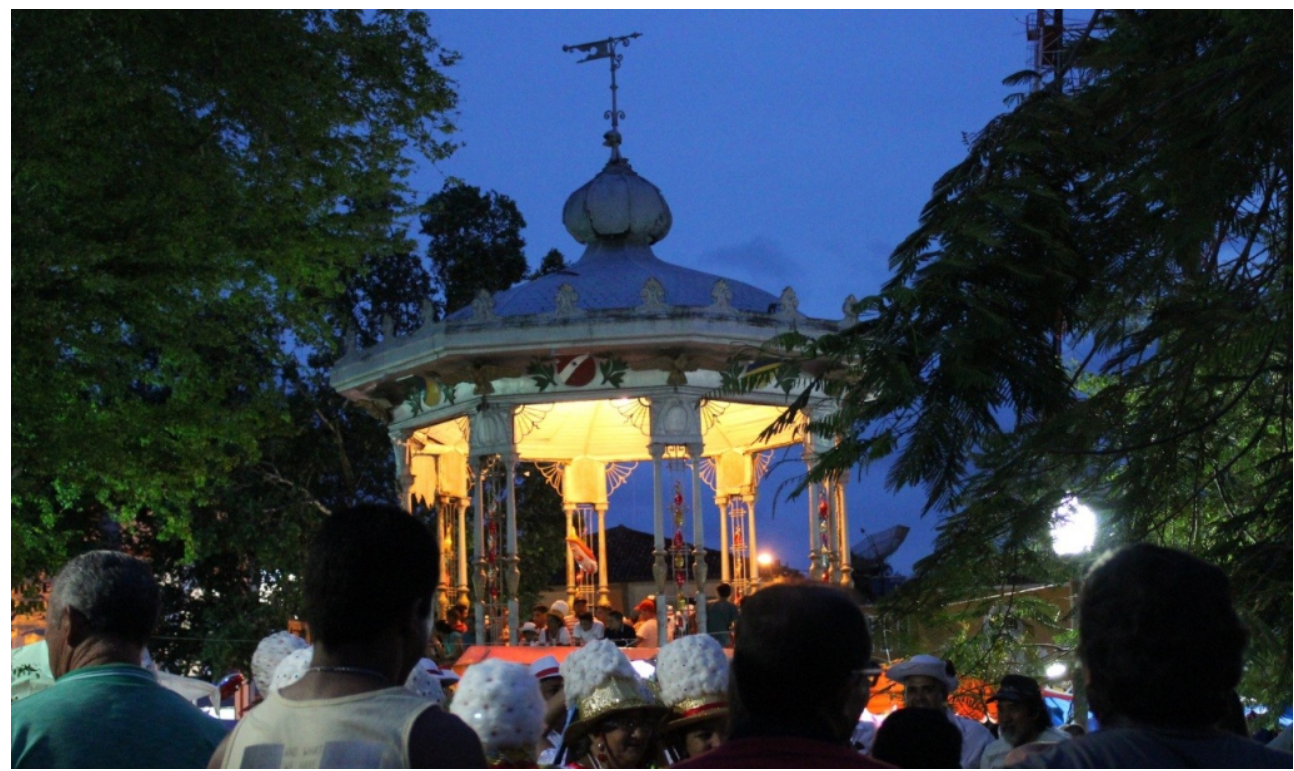

O coreto iluminado: música e dança na noite da cidade. Foto: Ronney Alano.

\section{Notas:}

1. Situada no nordeste paraense, a pouco mais de $200 \mathrm{~km}$ de Belém, Bragança possui população estimada em 122881 pessoas, com uma densidade demográfica de 54.13 hab $/ \mathrm{km}^{2}$ e está localizada à margem esquerda do rio Caeté, daí o porquê do título de "Pérola do Caeté", fonte: http://www.cidades.ibge.gov.br/v3/cidades/municipio/1501709, (consulta em 20.01.2017). Deve-se notar ainda que a cidade é bastante conhecida do povo paraense, sobretudo na chamada Região do Salgado, não apenas pela expressiva manifestação cultural em torno da Marujada, mas também pela herança arquitetônica de origem colonial parcialmente preservada, bem como pela memória da extinta estrada de ferro Belém-Bragança, inaugurada por volta de 1908 e desativada no final da primeira metade do século XX. Fonte para a história da ferrovia: http://www.correiobragantino.com.br/arq trem/trem.html, (consulta em 22.01.2017).

2. Segundo pesquisadores da cultura local, como o linguista José Guilherme Fernandes e o historiador Dário Benedito Rodrigues, a tradição de cultuar São Benedito, em Bragança, surgiu de um acordo entre negros escravizados e seus senhores, no final do século XVIII. Deste modo, aos negros ficava licenciada a prática de culto religioso e a construção de uma igreja, desde que dedicada a um santo católico de sua devoção, ao que estes últimos, não por acaso, elegeram "O santo preto". Para compreender melhor as implicações e desdobramentos políticos e sociais desse acordo, assim como os aspectos ritualísticos e musicais da Marujada, ver o documentário Beneditos, fonte: https://youtu.be/wxvyxEYIKql, (consulta em 14.01.2017).

3. Todo material fotográfico deste ensaio, capturado em 2016, concentra-se na programação do dia 26 de dezembro, quando ocorre a grande procissão. Mas, todos os anos, a Marujada começa bem antes. Já por volta do mês de março tem início a chamada "esmolação", momento em que as três imagens auxiliares de São Benedito percorrem três diferentes direções das cercanias: os Campos, as Praias e as Colônias - em busca de donativos. O alcance dessa peregrinação chega até as fronteiras com o estado do Maranhão, cf. Dário Bendito Rodrigues, em seu artigo História da Igreja de São Benedito em Braganca, fonte: http://profdariobenedito.blogspot.com.br/search?q $=$ Hist $\%$ C $3 \%$ B 3ria + da + Igreja+ de $+\mathrm{S} \% \mathrm{C} 3 \% \mathrm{~A} 3 \mathrm{o}+\mathrm{Benedito}+\mathrm{em}+\mathrm{Bragan} \% \mathrm{C} 3 \% \mathrm{~A} 7 \mathrm{a}$, (consulta em 14.01.2017). Para um 
enfoque antropológico do fluxo migratório de bragantinos que mantiveram consigo a tradição de cultuar São Benedito na região metropolitana de Belém, ver a dissertação de mestrado de Sônia Cristina de Albuquerque Vieira, intitulada “'É um pessoal lá de Bragança...': Um estudo antropológico acerca de identidades de migrantes em uma festa para São Benedito em A n a n i d e u / P A , f o n t e : http://www.ppgcs.ufpa.br/arquivos/dissertacoes/dissertacaoTurma2006SoniaVieira.pdf, (consulta em 22.01.2017).

4. Este, entre todos, é o mais popular epiteto de São Benedito, o que parece facilitar os mecanismos de identificação com a gente mais humilde e sofrida e com o povo negro em geral. A esse propósito, no entanto, é curioso notar, na atual tradição religiosa de Bragança, um certo apagamento das demais nuances da herança cultural dos negros, como bem observa José Guilherme Fernandes: "O próprio discurso religioso tenta fazer aquilo que Darcy Ribeiro chama de assimilação, ou seja, tratar todo mundo como igual. Então, você inclui a história [do negro], mas não dá visibilidade para esse elemento. Todos falam que a manifestação veio dos negros, mas não aceitam que haja uma ligação entre a umbanda, a pajelança e a devoção ao Santo, $\mathrm{p} \mathrm{or} \quad \mathrm{ex} \mathrm{e} \mathrm{m} \mathrm{p} \mathrm{lo",} \mathrm{fon} \mathrm{t} \mathrm{e} \mathrm{:}$ http://www.jornalbeiradorio.ufpa.br/novo/index.php/2011/132-edicao-100-dezembro/1285-as-vozes-da-devocao-em-braganca, (consulta em 23.01.2017).

5. Esta Irmandade foi criada em 1798, resultante do acordo descrito na nota 2, vindo a ser extinta quase duzentos anos depois. Entretanto, o termo permanece bastante vivo na memória coletiva do povo de Bragança, sendo ainda muito frequentemente mencionado. Ainda de acordo com Dário Benedito Rodrigues, em entrevista realizada via rede social (chat do Facebook, no dia 14.01.2017: “A Irmandade de 1798 foi extinta em 1988 após o processo na Justiça. Na década de 1980, fundaram outra associação que chamaram erradamente de irmandade (termo canônico) e que tomou conta e reponsabilidade da parte cultural que é a Marujada. Assim, ficou a nova associação com a palavra irmandade em sua denominação, mas não é aquela que foi criada no século $18 "$.

6. No dia 26 de dezembro, por ocasião da grande procissão, é comum ver nas janelas de alguns antigos casarões coloniais - ainda bem conservados em suas estruturas e na riqueza de detalhes dos objetos de época, como brasões de família -, pomposas imagens de São Benedito; provável resquício da interação cultural entre os senhores de origem europeia e os negros, por conta do culto ao santo.

7. À primeira vista, uma curiosidade quase pueril chamou minha atenção para a figura do marujo. Apenas a mais imediata relação me parecia óbvia: a do marujo com o mar. Mas qual seria a conexão com São Benedito? José Guilherme Fernandes, em entrevista concedida via e-mail no dia 16.01.17, responde: "Não vejo ligação direta com a possibilidade de remeter ao mar, no caso a prática pesqueira imediata de Bragança. O que se intitula marujada tem ligação mais direta com a nau catarineta, ritual de tradição portuguesa, que é representada por marujos e faz relação direta com o mar (...), talvez alusão ao movimento das grandes navegações de Portugal. Também existe marujada no sul do Brasil com o nome de fandango (...), ou seja, vem de uma tradição lusitana, mas que incorporou elementos fortes da tradição afrobrasileira”. Fernandes é autor do livro Pés que andam, pés que dançam: memória, identidade e região cultural na esmolação e marujada de São Benedito em Bragança (PA). 